\title{
АССОЦИАЦИЯ ГЕНЕТИЧЕСКИХ МАРКЕРОВ С АРТЕРИАЛЬНОЙ ГИПЕРТЕНЗИЕЙ В СИБИРСКОЙ ПОПУЛЯЦИИ
}

Максимов В. Н. ${ }^{1,2}$, Орлов П. С. ${ }^{1,2}$, Малютина С. К. ${ }^{1}$, Маздорова Е. В. ${ }^{1}$, Никитин Ю. П. ${ }^{1}$, Воевода М. И. ${ }^{1,2}$

Цель. Проверить однонуклеотидные полиморфизмы (ОНП), идентифицированные в недавних ассоциативных исследованиях на пригодность в качестве маркёров риска развития артериальной гипертензии (АГ) в сибирской популяции.

Материал и методы. Группа больных АГ и контрольная группа (отношение 2:1) были сформированы на основе популяционной выборки 45-69 летних жителей г. Новосибирска (9400 человек), которая была собрана в ходе работы по международному проекту HAPIEE. В исследование включены 514 человек, из них контрольная группа - 168 человек (127 мужчин и 41 женщина) с АД не выше "нормального" по данным 2-х и более обследований в течение нескольких лет с интервалом не менее 6 мес. Группа с АГ состоит из 346 человек (206 мужчин и 140 женщин) с установленным диагнозом АГ. Геномную ДНК выделяли из венозной крови методом фенол-хлороформной экстракции Полиморфизм генов тестировали с помощью ПцР в реальном времени в соответствии с протоколом фирмы производителя (зонды TaqMan, Applied Biosystems, USA) на приборе ABI 7900НT. В исследование были взяты следующие ОНП: rs699 ген AGT, rs5068 ген NPPB, rs17367504 ген MTHFR, rs2681492 ген ATP2B1, rs4343 ген ACE, rs1801253 ген ADRB1, rs11240692 ген REN, rs2846679 ген KCNJ1, rs239345 ген SCNN1B, rs1799983 ген NOS3.

Результаты. Отношение шансов иметь АГ у мужчин - носителей генотипа GG rs699 гена AGT - составило 1,95 (95\% ДИ 1,08-3,53; p=0,003) по сравнению с носителями двух других генотипов. Носительство генотипа AA rs699 напротив, является условно протективным фактором в отношении развития АГ у мужчин (ОШ 0,47; 95\% ДИ 0,27-0,81; p=0,007)

Заключение. Для двух из десяти исследованных ОНП была подтверждена ассоциация с АГ у мужчин: rs699 гена AGT и rs5068 гена NPPB.

Российский кардиологический журнал 2014, 10 (114): 73-76

http://dx.doi.org/10.15829/1560-4071-2014-10-73-76
Ключевые слова: артериальная гипертензия, однонуклеотидный полиморфизм, rs699, AGT, rs5068, NPPB.

'ФГБУ Научно-исследовательский институт терапии и профилактической

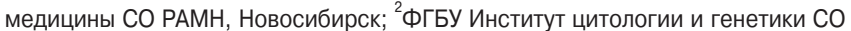
РАН, Новосибирск, Россия.

Максимов В.Н. * - д.м.н., зав. лабораторией молекулярно-генетических исследований терапевтических заболеваний, Орлов П. С. - М.н.с. лаборатории молекулярно-генетических исследований терапевтических заболеваний, Малютина С. К. - д.м.н., профессор, зав. лабораторией этиопатогенеза и клиники внутренних заболеваний, Маздорова Е. В. - К.м.н., Н.с. лаборатории неотложной терапии, Никитин Ю.П. - д.м.н., профессор, академик РАМН, лаборатория этиопатогенеза и клиники внутренних заболеваний, Воевода М.И. - д.м.н., профессор, член-корреспондент РАМН, директор института.

*Автор, ответственный за переписку (Corresponding author): medik11@mail.ru

АГ - артериальная гипертензия, АД - артериальное давление, ДНК - дезоксирибонуклеиновая кислота, ИБС - ишемическая болезнь сердца, ОНП однонуклеотидный полиморфизм, ПцР - полимеразная цепная реакция, СС3 - сердечно-сосудистые заболевания, ОМІM - Online Mendelian Inheritance in Man, HAPIEE - Health, Alcohol and Psychosocial factors In Eastern Europe.

Рукопись получена 01.04.2014

Рецензия получена 11.04.2014

Принята к публикации 18.04.2014

\section{ASSOCIATION OF GENETIC MARKERS IN HYPERTENSIVE DISEASE IN SIBERIAN POPULATION}

\author{
Maximov V. N. ${ }^{1,2}$, Orlov P. S. ${ }^{1,2}$, Malyutina S. K. ${ }^{1}$, Mazdorova E. V. ${ }^{1}$, Nikitin Yu. P. ${ }^{1}$, Voevoda M. I. ${ }^{1,2}$
}

Aim. To check whether the mononucleotide polymorphisms (MNP), identified in recent studies do match a risk marker criteria for arterial hypertension $(\mathrm{AH})$ in Siberian population.

Material and methods. The group of subjects with $\mathrm{AH}$ and control group (relation $2: 1)$ were formed from the population selection of 45-69 years old citizens of Novosibirsk ( 9400 subjects), which had been collected during the work in HAPIEE project. Totally 514 subjects included, of those controls - 168 (127 men and 41 women) with BP not higher than "normal" by the data of 2 and more examinations during the last years, with interval not more than 6 months. Group with AH consists of 346 subjects ( 206 men and 140 women) with the diagnosis of $\mathrm{AH}$. Genomic DNA was extracted from venous blood by the method of phenol-chloroform extraction. Gene polymorphism was tested by PCR in real time according to the protocol of equipment manufacturer (zonds TagMan, Applied Biosystems, USA) on the device $\mathrm{ABI} 7900 \mathrm{HT}$. These MNP were included into the study: rs699 gene $A G T$, rs5068 gene NPPB, rs17367504 gene MTHFR, rs2681492 gene ATP2B1, rs4343 gene ACE rs1801253 gene $A D R B 1$, rs11240692 gene REN, rs2846679 gene $K C N J 1$, rs239345 gene SCNN1B, rs1799983 gene NOS3.

В настоящее время эссенциальная артериальная гипертензия (АГ) является одним из основных факторов риска развития неблагоприятных исходов целого ряда внутренних болезней. Развитие артериальной гипертензии как мультифакториального заболевания определяется взаимодействием генетически детерми-
Results. The risk relation to develop AH in men - carriers of GG rs699 gene AGT was 1,95 (95\% Cl 1,08-3,53; $p=0,003$ ) comparing to the carriers of two other genotypes. Carriage of AA genotype rs699, opposite, is probably protective factor for $\mathrm{AH}$ development in men (HR 0,47; 95\% Cl 0,27-0,81; $p=0,007$ ).

Conclusion. For two from ten MNP studied the association with $\mathrm{AH}$ was confirmed in men: rs699 gene AGT and rs5068 gene NPPB.

Russ J Cardiol 2014, 10 (114): 73-76

http://dx.doi.org/10.15829/1560-4071-2014-10-73-76

Key words: arterial hypertension, mononucleotide polymorphism, rs699, AGT, rs5068, NPPB.

${ }^{1}$ FSBI Scientific-Research Institute for Therapy and Preventive Medicine of the SD RAMS, Novosibirsk; ${ }^{2}$ FSBI Institute for Cytology and Genetics of the SD RAMS, Novosibirsk; Russia.

нируемой предрасположенности и средовых факторов. Распространённость наследственной отягощённости по АГ у мужчин в Новосибирске составляет $38,7 \%$ [1]. Многими работами установлен достаточно высокий уровень наследуемости фенотипической вариабельности артериального давления (АД) - от $30 \%$ до 50\% [2]. 
В генетических исследованиях факторов развития АГ идентифицировано более 1500 генов, которые ассоциированы с повышением уровня АД [3]. Из них около 200 обнаружены или подтверждены при выполнении GWAS, ещё почти на 200 имеются мета-анализы, следовательно, выполнен колоссальный объём работы. В то же время, существенная доля результатов - противоречива, а полученные эффекты отдельных полиморфизмов - слабы [2]. Именно это, по сути, является подтверждением классического представления о множестве факторов, влияющих на артериальное давление, которое определяется вкладом многих генов с незначительным эффектом каждого во взаимодействии со средовыми факторами.

Несмотря на то, что в целом идентифицированные генетические маркеры объясняют небольшую долю фенотипической дисперсии (менее 5\%), тем не менее, на их основе уже тестируются генетические рискометры для заблаговременной оценки вероятности развития артериальной гипертензии. Причины недостаточной статистической значимости и отрицательных результатов репликации более ранних исследований, а также небольшая величина вклада генетических факторов по результатам полногеномных исследований могут быть связаны с методологией исследования (фенотип, дизайн), этническими особенностями, вкладом средовых факторов, недостаточной плотностью маркеров и другими технологическими параметрами, а также зависят собственно от сложности патогенеза АГ. Всё это делает актуальным проведение реплицирующих исследований на каждой этнической группе, популяции, проживающих в специфических условиях среды, отличающихся по характеру питания и целому ряду других факторов.

\section{Материал и методы}

В исследование включены 514 человек. В контрольную группу вошли 168 человек (127 мужчин и 41 женщина) с АД не выше "нормального" по данным 2-х и более обследований в течение нескольких лет с интервалом не менее 6 мес. Группа с АГ состоит из 346 человек (206 мужчин и 140 женщин) с установленным диагнозом АГ. Собраны медицинские данные на основании стандартизованного опросника и медицинской документации (история АГ и гипотензивная терапия; оценка наследственной отягощенности по АГ и СС3; социально-демографические характеристики). Выполнены клинические измерения АД в 2-сессиях, с промежутком в 1 неделю. Протокол исследования был одобрен Этическим комитетом ФГБУ “НИИТПМ” СО РАМН. До включения в исследование у всех участников было получено письменное информированное согласие. Группы были сформированы на основе популяционной выборки 45-69 летних жителей Октябрьского и Кировского районов г. Новосибирска (9400 человек), которая была собрана НИИ терапии СО РАМН в ходе работы по международному проекту HAPIEE (Health, Alcohol and Psychosocial factors In Eastern Europe). Программа исследования включала: измерение артериального давления, антропометрия (рост, вес, объём талии, бёдер), социально-демографические характеристики, опрос о курении, потреблении алкоголя (частота и типичная доза), уровне физической активности, оценку липидного профиля (общий холестерин; триглицериды, холестерин липопротеидов высокой плотности), опрос на выявление стенокардии напряжения (Rose), ЭКГ покоя в 12-ти отведениях.

Геномную ДНК выделяли из 10 мл венозной крови. Образцы крови для экстракции ДНК хранили при температуре $-20^{\circ}$ С. Экстракция ДНК из крови проводилась фенол-хлороформным методом. Однонуклеотидные полиморфизмы (ОНП) тестировали с помощью ПЦР в реальном времени, с анализом по конечной точке, в соответствии с протоколом фирмы производителя (зонды TaqMan, Applied Biosystems, USA) на приборе ABI 7900НТ. Генотипирование было выполнено для 10 ОНП. Перечень ОНП с краткой информацией по каждому представлен в таблице 1.

Ассоциация ОНП с АГ проверялась с помощью таблиц сопряжённости с использованием критерия хи-квадрат по Пирсону. В случае четырёхпольных таблиц сравнение выборок по частотам генотипов и аллелей применяли точный двусторонний критерий Фишера. Относительный риск заболевания по конкретному аллелю или генотипу вычисляли как отношение шансов.

\section{Результаты и обсуждение}

По результатам генотипирования, на первом этапе определяли частоты генотипов и аллелей, изучаемых ОНП в группе больных АГ и контрольной группе, затем оценивали соответствие распределения частот генотипов равновесию Харди-Вайнберга в контрольной группе (по критерию хи-квадрат). У всех исследуемых ОНП распределение частот генотипов соответствовало равновесию Харди-Вайнберга. Статистиче-

Таблица 1

Краткая информация по ОНП, отобранным для анализа

\begin{tabular}{|l|l|l|l|l|}
\hline Rs & Ген & Хромосомная локализация & Выборка & Сссылка \\
\hline rs699 & AGT & $1 \mathrm{q} 42-q 43$ & 18436 & 4 \\
\hline rs5068 & NPPB & $1 \mathrm{p} 36.2$ & 29717 & 7 \\
\hline rs17367504 & MTHFR & 1 & 87273 & 8 \\
\hline rs2681492 & ATP2B1 & 12 & 63659 & 9 \\
\hline rs4343 & ACE & $17 q 23$ & 1699 & 10 \\
\hline rs1801253 & ADRB1 & $10 q 24-q 26$ & & 11 \\
\hline rs11240692 & REN & $1 q 32$ & 86588 & 4 \\
\hline rs2846679 & KCNJ1 & $11 q 24.3$ & 7677 & 12 \\
\hline rs239345 & SCNN1B & $16 p 12.2$ & 2379 & 13 \\
\hline rs1799983 & NOS3 & $7 q 36.1$ & 2037 & 14 \\
\hline
\end{tabular}


Таблица 2

Частоты генотипов ОНП в группе с АГ и контрольной группе (мужчины и женщины, 45-69 лет, г. Новосибирск)

\begin{tabular}{|c|c|c|c|c|c|c|}
\hline \multirow[t]{2}{*}{$\mathrm{OH} \Pi$} & \multirow[t]{2}{*}{ Генотипы } & \multicolumn{2}{|c|}{ Контрольная группа } & \multicolumn{2}{|l|}{$\mathrm{A} \Gamma$} & \multirow[t]{2}{*}{$p$} \\
\hline & & $n$ & $\%$ & $n$ & $\%$ & \\
\hline \multirow[t]{3}{*}{ rs699 } & AA & 45 & 28,8 & 62 & 21 & \multirow[t]{3}{*}{0,092} \\
\hline & $A G$ & 83 & 53,2 & 160 & 54,2 & \\
\hline & GG & 28 & 17,9 & 73 & 24,7 & \\
\hline \multirow[t]{3}{*}{ rs4343 } & AA & 42 & 26,8 & 86 & 29,3 & \multirow[t]{3}{*}{0,103} \\
\hline & $A G$ & 69 & 43,9 & 148 & 50,3 & \\
\hline & GG & 46 & 29,3 & 60 & 20,4 & \\
\hline \multirow[t]{2}{*}{ rs5068 } & GG & 132 & 86,3 & 268 & 91,2 & \multirow[t]{2}{*}{0,110} \\
\hline & GT & 21 & 13,7 & 26 & 8,8 & \\
\hline \multirow[t]{3}{*}{ rs239345 } & AA & 10 & 6,5 & 10 & 3,4 & \multirow[t]{3}{*}{0,226} \\
\hline & AT & 59 & 38,6 & 105 & 35,8 & \\
\hline & TT & 84 & 54,9 & 178 & 60,8 & \\
\hline \multirow[t]{3}{*}{ rs1799983 } & GG & 86 & 55,1 & 168 & 57,3 & \multirow[t]{3}{*}{0,672} \\
\hline & GT & 57 & 36,5 & 107 & 36,5 & \\
\hline & $\mathrm{TT}$ & 13 & 8,3 & 18 & 6,1 & \\
\hline \multirow[t]{3}{*}{ rs1801253 } & $\mathrm{CC}$ & 69 & 46,3 & 152 & 52,6 & \multirow[t]{3}{*}{0,441} \\
\hline & CG & 70 & 47 & 118 & 40,8 & \\
\hline & GG & 10 & 6,7 & 19 & 6,6 & \\
\hline \multirow[t]{3}{*}{ rs2846679 } & AA & 1 & 0,6 & 4 & 1,4 & \multirow[t]{3}{*}{0,177} \\
\hline & $A G$ & 46 & 29,5 & 65 & 22,0 & \\
\hline & GG & 109 & 69,9 & 227 & 76,7 & \\
\hline \multirow[t]{3}{*}{ rs11240692 } & $\mathrm{CC}$ & 66 & 42,6 & 134 & 45,4 & \multirow[t]{3}{*}{0,783} \\
\hline & CT & 71 & 45,8 & 125 & 42,4 & \\
\hline & $\mathrm{TT}$ & 18 & 11,6 & 36 & 12,2 & \\
\hline \multirow[t]{3}{*}{ rs17367504 } & AA & 115 & 73,2 & 222 & 76,0 & \multirow[t]{3}{*}{0,703} \\
\hline & $A G$ & 40 & 25,5 & 68 & 23,3 & \\
\hline & GG & 2 & 1,3 & 2 & 0,7 & \\
\hline \multirow[t]{3}{*}{ rs2681492 } & $\mathrm{CC}$ & 0 & 0 & 3 & 1,0 & \multirow[t]{3}{*}{0,419} \\
\hline & CT & 40 & 25,5 & 70 & 23,6 & \\
\hline & TT & 117 & 74,5 & 223 & 75,3 & \\
\hline
\end{tabular}

ски значимых различий по частотам генотипов исследованных ОНП между контрольной группой и группой с АГ не получено (табл. 2). Но по частотам аллелей rs699 гена $A G T$ они имеются. Отношение шансов иметь АГ у носителей аллеля $\mathrm{G}$ составляет 1,34 (95\% ДИ 1,02-1,77; $=0,042)$.

На следующем этапе анализа группы разделили по полу. У женщин статистически значимых различий по частотам генотипов исследованных ОНП между контрольной группой и группой с АГ не получено. В таблицу 3 включены данные по обнаруженным изолированно у мужчин достоверным связям ОНП с АГ.

Подтверждена ассоциация полиморфизма rs699 в гене $A G T$ с артериальной гипертензией у мужчин. Ген $A G T$, расположен на длинном плече 1-й хромосомы (1q42-q43). Замена аминокислоты метионина на тирозин в белке (М235T) происходит вследствие замены тимина на цитозин в нуклеотидной последовательности (rs699). По данным Conen D. и соавторов, (2008) этот ОНП ассоциирован с развитием и прогрессированием артериальной гипертензии [4]. В недавнем мета-анализе Takeuchi et al., (2012) на 19426 обследованных японцев подтверждена связь rs699 гена $A G T$ в японской популяции [5]. Вклад полиморфизма $A G T$ в развитие АГ связывают с повышением ангиотензиногена в плазме крови [6], влиянием на инсулинорезистентность. На нашей общей группе различий по частотам генотипов нет. При разделении по полу статистически значимые отличия обнаружены у мужчин $(p=0,008)$. Отношение шансов иметь АГ у мужчин - носителей генотипа GG составило 1,95 (95\% ДИ 1,08-3,53; p=0,003) по сравнению с носителями двух других генотипов. Носительство генотипа АА напротив, является условно протективным фактором в отношении развития АГ у мужчин (ОШ 0,47; 95\% ДИ 0,27-0,81; $\mathrm{p}=0,007)$. Различия в частотах аллелей между группами мужчин с АГ и нормотензией также оказались достоверными: носительство аллеля $\mathrm{G}$ ассоциировано с повышением риска иметь АГ (ОШ 1,66; 95\% ДИ 1,19-2,31; $=0,003)$.

Генотип ОНП rs5068 расположен на коротком плече 1-й хромосомы (1p36.22), относится сразу к трём генам: 1) ген $N P P B$ (OMIM 600295), natriuretic peptide precursor B, 2) ген NPPA-AS1 NPPA antisense RNA 1,3) ген CLCN6 (OMIM 602726), chloride channel, voltagesensitive 6. В обследованной выборке в отношении rs5068, ген $N P P B$ была получена пограничная связь с артериальной гипертензией у мужчин, частота АГ 
Таблица 3

Частоты генотипов ОНП, различающиеся в группах АГ и контроле у мужчин, 45-69 лет, г. Новосибирск

\begin{tabular}{|c|c|c|c|c|c|c|}
\hline \multirow[t]{2}{*}{$\mathrm{OH} \Pi$} & \multirow[t]{2}{*}{ Генотипы } & \multicolumn{2}{|c|}{ Контрольная группа } & \multicolumn{2}{|l|}{$\mathrm{A} \Gamma$} & \multirow[t]{2}{*}{$p$} \\
\hline & & $\mathrm{n}$ & $\%$ & $\mathrm{n}$ & $\%$ & \\
\hline \multirow[t]{3}{*}{ rs699 } & AA & 37 & 31,4 & 31 & 17,7 & \multirow[t]{3}{*}{0,008} \\
\hline & $A G$ & 61 & 51,7 & 96 & 54,9 & \\
\hline & GG & 20 & 16,9 & 48 & 27,4 & \\
\hline \multirow[t]{2}{*}{ rs5068 } & GG & 101 & 87,1 & 165 & 93,8 & \multirow[t]{2}{*}{0,050} \\
\hline & $A G$ & 15 & 12,9 & 11 & 6,3 & \\
\hline
\end{tabular}

была ниже у носителей гетерозиготного генотипа $(\mathrm{p}=0,05)$, таблица 3. Это соответствует данным литературы. В частности, в мета-анализе Newton-Cheh C, et al., (2009) получено снижение АДС, АДД и шансов АГ (на 10\%) у носителей минорного аллеля [7, 8]. Потенциальные механизмы ассоциации связывают с более высокими концентрациями плазменных предсердного и В-типа натрийуретических пептидов [7]. А по данным Fedorowski А и соавторов (2012) rs5068 ассоциирован с ортостатической гипотензией [16].

Таким образом, из 10 ОНП генов-кандидатов АГ на удовлетворительной по объёму и критериям формирования выборке удалось подтвердить ассоциацию только для двух — rs699 и rs5068.

\section{Заключение}

Относительно небольшое количество подтверждённых нами на сибирской популяции ассоциаций, с одной стороны, ещё раз доказывает, что необходимо проверять на возможность использования маркёры, обнаруженные при исследованиях других популяций, с другой, заставляет искать новые подходы к решению проблемы поиска прогностически информативных маркёров повышенного риска развития патологического фенотипа. Маркёры, обнаруженные при исследованиях других популяций, могут оказаться

\section{Литература}

1. Nikitin luP, Voevoda MI, Maksimov VN, et al. Arterial hypertension and its relation to hereditary burden (family history) in male population of Novosibirsk (WHO MONICA Program)]. Kardiologiia 2005; 45(8): 44-5. Russian (Никитин Ю.П., Воевода М.И., Максимов В.Н., и др. Артериальная гипертензия и её связь с наследственной отягощенностью в мужской популяции Новосибирска (программа ВОЗ MONICA). Кардиология 2005; 45(8): 44-5).

2. Snieder $\mathrm{H}$, Harshfield GA, Treiber FA. Heritability of blood pressure and hemodynamics in African- and European-American youth. Hypertension. 2003 Jun; 41(6): 1196-201.

3. http://hugenavigator.net/ HuGENavigator/startPagePhenoPedia.do.

4. Conen D, Glynn RJ, Buring JE, et al. Association of renin-angiotensin and endothelial nitric oxide synthase gene polymorphisms with blood pressure progression and incident hypertension: prospective cohort study. J Hypertens. 2008 Sep; 26(9): 1780-6.

5. Takeuchi F, Yamamoto K, Katsuya T, et al. Reevaluation of the association of seven candidate genes with blood pressure and hypertension: a replication study and meta-analysis with a larger sample size. Hypertens Res. 2012; 35(8): 825-31.

6. Sethi AA, Nordestgaard BG, Tybjaerg-Hansen A. Angiotensinogen gene polymorphism, plasma angiotensinogen, and risk of hypertension and ischemic heart disease: a metaanalysis. Arterioscler Thromb Vasc Biol. 2003; Jul 1, 23(7): 1269-75.

7. Newton-Cheh C, Larson MG, Vasan RS, et al. Association of common variants in NPPA and NPPB with circulating natriuretic peptides and blood pressure. Nat Genet. $2009 \mathrm{Mar} ;$ 41(3): 348-53.

8. Newton-Cheh C, Johnson T, Gateva V, et al. Genome-wide association study identifies eight loci associated with blood pressure. Nat Genet. 2009 Jun; 41(6): 666-76. мономорфными или с очень низкой частотой “аллеля риска", могут не ассоциироваться с фенотипом, к примеру, из-за принадлежности к другому блоку сцепления в нашей популяции. Дополнительные неизвестные в уравнение добавляют специфические климатические и диетические особенности нашей популяции. Как известно, внешние факторы могут влиять даже на экспрессивность и пенетрантность классических моногенных заболеваний и, тем более, их приходится учитывать при мультифакториальных заболеваниях. Задача усложняется, когда мы имеем дело не с обычным количественным признаком (артериальное давление), а с заболеванием (артериальная гипертензия) и называем преодоление какойто условной границы. Одним из путей решения проблемы может стать формирование фенотипически однородных групп не только по полу и возрасту, но и по ведущим патогенетическим факторам.

Благодарность. Работа частично поддержана грантом фонда РФФИ № 13-04-01955, интеграционным проектом фундаментальных исследований СО РАН № 01201257565, грантом ФЦП № 2010-1.1-234-069058. Проект HAPIEE поддержан грантами Wellcome Trust (081081/Z/06/Z), National Institute of Aging (1R01 AG23522).

9. Levy D, Ehret GB, Rice K, et al. Genome-wide association study of blood pressure and hypertension. Nat Genet. 2009 Jun; 41(6): 677-87.

10. Wenquan Niu, Yue Qi, Pingjin Gao, et al. Review: association between angiotensin converting enzyme G2350A polymorphism and hypertension risk: a meta-analysis. J Renin Angiotensin Aldosterone Syst. $2011 \mathrm{Mar} ;$ 12(1): 8-14.

11. Chung CM, Wang RY, Chen JW, et al. A genome-wide association study identifies new loci for ACE activity: potential implications for response to ACE inhibitor. Pharmacogenomics J. 2010 Dec; 10(6): 537-44

12. Gjesing AP, Andersen G, Albrechtsen A, et al. Studies of associations between the Arg389Gly polymorphism of the beta1-adrenergic receptor gene (ADRB1) and hypertension and obesity in7677 Danish white subjects. Diabet Med. 2007 Apr; 24(4): 392-7.

13. Ehret GB, O'Connor AA, Weder A, et al. Follow-up of a major linkage peak on chromosome 1 reveals suggestive QTLs associated with essential hypertension: GenNet study. Eur J Hum Genet. 2009 Dec; 17(12): 1650-7.

14. Tobin MD, Tomaszewski M, Braund PS, et al. Common variants in genes underlying monogenic hypertension and hypotension and blood pressure in the general population. Hypertension. 2008 Jun; 51(6): 1658-64.

15. Zhao Q, Gu D, Hixson JE, et al. Genetic Epidemiology Network of Salt Sensitivity Collaborative Research Group. Common variants in epithelial sodium channel genes contribute to salt sensitivity of blood pressure: The GenSalt study. Circ Cardiovasc Genet. 2011 Aug 1; 4(4): 375-80.

16. Fedorowski A. Franceschini N, Brody J, et al. Orthostatic hypotension and novel blood pressure-associated gene variants: Genetics of Postural Hemodynamics (GPH) Consortium. Eur Heart J. 2012 Sep; 33(18): 2331-41. 